\title{
ÁCIDOS GRASOS, FERMENTACIÓN RUMINAL Y PRODUCCIÓN DE METANO, DE FORRAJES DE SILVOPASTURAS INTENSIVAS CON LEUCAENA ${ }^{1}$
}

\author{
Esperanza Prieto-Manrique ${ }^{2}$, Julio Ernesto Vargas-Sánchez ${ }^{3}$, Joaquín Angulo-Arizala ${ }^{4}$, \\ Liliana Mahecha-Ledesma ${ }^{4}$
}

\section{RESUMEN}

Ácidos grasos, fermentación ruminal y producción de metano, de forrajes de silvopasturas intensivas con Leucaena. El objetivo del presente trabajo fue determinar el efecto de los forrajes sobre los ácidos grasos de cadena larga, fermentación ruminal y producción de metano de un sistema silvopastoril intensivo de Leucaena leucocephala. La investigación se desarrolló en el laboratorio NUTRILABGRICA, perteneciente a la Facultad de Ciencias Agrarias, de la Universidad de Antioquia, Medellín-Colombia, en julio del 2013. Se utilizó la técnica de producción de gas in vitro, utilizando como sustrato de fermentación las gramíneas $(C$. plectostachyus y/o M. maximus cv. Tanzania) y leucaena (L. leucocephala), solas o en sus combinaciones, con una relación forraje:concentrado 70:30 y gramínea: leucaena 56:14, para un total de siete tratamientos. No se encontró efecto de los forrajes $(\mathrm{p}>0,05)$, sobre el contenido de ácido linoleico conjugado (ALC, C18:2 c9t11) o ruménico en la digesta. La inclusión de $14 \%$ de leucaena aumentó el contenido de ácido linoleico $(\mathrm{C} 18: 2 \mathrm{c} 9,12)$ y linolénico (C18:3 c9, 12, 15) en el alimento y de transvaccénico (ATV, C18:1 t11), esteárico (C18:0), linoleico y linolénico en la digesta $(\mathrm{p}<0,05)$, y no afectó la cinética de fermentación, digestibilidad de la materia seca (MS), $\mathrm{pH}$, total y proporción de ácidos grasos volátiles, ni redujo la producción de metano. Las gramíneas, C. plectostachyus y M. maximus, se comportaron similar en las variables evaluadas $(\mathrm{p}>0,05)$. Los sistemas silvopastoriles pueden ser una opción para aumentar los ácidos grasos benéficos en la leche.

Palabras clave: ácido linoleico conjugado, ácido transvaccénico, Cynodon plectostachyus, Megathyrsus maximus cv. Tanzania, sistema silvopastoril.

\begin{abstract}
Fatty acids, ruminal fermentation, and methane production, of forage in intensive silvopastures with Leucaena. The aim of this study was to evaluate the effect of forages on the long chain fatty acids, ruminal fermentation, and methane production in an intensive silvopastoral system of Leucaena leucocephala. This study was developed in the laboratory NUTRILAB-GRICA, of the Faculty of Agricultural Sciences, University of Antioquia, Medellin-Colombia, in July 2013. The study was carried out by the in vitro gas production technique using grasses (C. plectostachyus and/or M. maximus cv. Tanzania) and leucaena (L. leucocephala) as substrate of fermentation, alone or with their combinations, with 70:30 forage:concentrate ratio and 56:14 grass: leucaena ratio for a total of seven treatments. No forage effect $(\mathrm{p}>0,05)$ on the conjugated linoleic fatty acid content (CLA, C18:2 c9t11) or rumenic acid, in the digesta was found. The inclusion of $14 \%$ of leucaena increased the content of linoleic $(\mathrm{C} 18: 2 \mathrm{c} 9,12)$ and linolenic $(\mathrm{C} 18: 3 \mathrm{c} 9,12,15)$ acids in food and transvaccenic (TVA, C18: 1 t11), stearic (C18: 0), linoleic and linolenic acids in the digesta $(\mathrm{p}<0.05)$, and did not affect the kinetics of fermentation, digestibility of dry matter, $\mathrm{pH}$, total and ratio volatile fatty acids, nor reduced methane production. Grasses, C. plectostachyus and M. maximus had a similar behavior in the evaluated variables $(p>0.05)$. Silvopastoral systems could be an option to increase the beneficial fatty acids in milk.
\end{abstract}

Keywords: conjugated linoleic acid, transvaccenic acid, Cynodon plectostachyus, Megathyrsus maximus cv. Tanzania, silvopastoral system.

\footnotetext{
Recibido: 27 de mayo, 2015. Aceptado: 13 de agosto, 2015. Este trabajo forma parte de un proyecto de investigación financiado por COLCIENCIAS - Colombia y es parte de la tesis doctoral del primer autor.

2 Universidad de Sucre, Facultad de Ciencias Agropecuarias. Carrera 28 N 5-267, Barrio Puerta Roja, Sincelejo -Sucre, Colombia. esperanza. prieto@unisucre.edu.co

3 Universidad de Caldas, Facultad de Ciencias Agropecuarias, Departamento de Producción Agropecuaria. Calle 65 N²6-10, Manizales Caldas, Colombia.jvargas@ucaldas.edu.co

4 Universidad de Antioquia, Facultad de Ciencias Agrarias, Grupo de Investigación en Ciencias Animales - GRICA. Sede Robledo, carrera 75 N ${ }^{\circ}$ 65-87 bloque 46, Medellín - Antioquia, Colombia. joaquin.angulo@udea.edu.co, Liliana.mahecha@udea.edu.co (autor para correspondencia).
} 


\section{INTRODUCCIÓN}

El ácido linoleico conjugado C18:2 cis9-trans11 (ALC c9t11) o ácido ruménico, el ácido transvaccénico (ATV) y algunos ácidos grasos de cadena larga (AGCL) $n$-3 de la leche bovina, se relacionan con beneficios para la salud humana (Harris, 2008). Así, ALC y ATV, resultan del consumo de ácidos grasos (AG) insaturados y de la extensión de la biohidrogenación ruminal, mientras que (AGCL) $n-3$ provienen de la dieta y de su capacidad para escapar a la biohidrogenación. La magnitud de las cantidades presentes en la leche está determinada principalmente por factores dietarios (Palmquist, 2007).

El contenido de ALC c9t11en la leche, es más elevado en animales que reciben raciones con una mayor proporción de forraje, esto también puede estar afectado por el tipo de forraje suministrado, siendo más alto en animales en pastoreo que cuando reciben forrajes conservados (ensilados) (Weiss et al., 2004a; b; Mele et al., 2006; Mohammed et al., 2006). El efecto enriquecedor de las pasturas sobre los niveles de ALC c9t11 en leche, se explica por el consumo de ácido linolénico proveniente del pasto, su posterior conversión en ATV (C18:1 trans11) como resultado de la biohidrogenación a nivel de rumen y la subsiguiente conversión a ALC c9t11, por actividad de la enzima mamaria delta- 9 desaturasa (Griinari y Bauman, 1999). Se estima, que más del $74 \%$ de ALC c9t11 en la grasa de la leche es sintetizado a través de la actividad de la enzima delta- 9 desaturasa (Bichi et al., 2012); por lo tanto, es necesario aumentar el flujo de ATV desde el rumen para aumentar el contenido de ALC c9t1len la leche.

Uno de los mayores contaminantes del medio ambiente es el metano, gas de efecto invernadero que tiene un potencial de calentamiento veintiún veces mayor que el dióxido de carbono (IPCC, 2007). A la producción agrícola se le atribuye $40 \%$ de la producción de metano originado en actividades humanas. La producción de metano entérica, principalmente de la ganadería, constituye la mayor fuente individual y alcanza de $15 \%$ a $20 \%$ de la producción global de gases efecto invernadero de origen antrópico (Lassey et al., 1997; Moss et al., 2000; Sheehle y Kruger, 2006). La producción ruminal de metano constituye una pérdida de eficiencia nutricional que alcanza de $6 \%$ a $8 \%$ de la energía bruta consumida, pero puede incluso llegar hasta $12 \%$ de la misma (Johnson y Johnson,
1995). Razón por la cual, la búsqueda de tecnologías que permitan reducir la producción de metano en condiciones comerciales, es tema de estudio.

En Colombia, el $45 \%$ de la leche se produce en lechería especializada y el 55\% bajo el sistema doble propósito (CONPES, 2010), que en su expresión tradicional se manejan bajo pastoreo con una base forrajera de solo gramíneas. Sin embargo, otros productores utilizan pastoreo en sistemas con una base forrajera silvopastoril, que permite aumentar la oferta de forraje, en particular durante el periodo seco, mejorar la calidad de la dieta a lo largo del año y mejorar la conservación y el reciclaje de nutrientes (Murgueitio, 1999; Pagiola et al., 2005; 2007). Hay evidencia de que metabolitos secundarios presentes en plantas forrajeras no gramíneas, pueden limitar la biohidrogenación ruminal (Khiaosa-Ard et al., 2009) y la producción de metano (Jayanegara et al., 2011; Tan et al., 2011). Adicionalmente, existe variación en la composición lipídica de los forrajes frescos (Krebsky et al., 1996; Addis et al., 2005; Cabiddu et al., 2009), que puede afectar la cantidad de ATV producido en el rumen.

El desarrollo de estrategias en la ganadería colombiana que permitan aumentar los ácidos grasos benéficos en la leche y disminuir la emisión de metano, exige un previo conocimiento de las condiciones de alimentación específicas del país; que varían de acuerdo al sistema de producción y a los procesos de fermentación ruminal que se generan en cada uno de ellos.

El objetivo de este trabajo fue determinar el efecto de los forrajes sobre los ácidos grasos de cadena larga, fermentación ruminal y producción de metano, de un sistema silvopastoril intensivo de Leucaena leucocephala.

\section{MATERIALES Y MÉTODOS}

\section{Localización}

Este trabajo fue desarrollado en el laboratorio NUTRILAB -GRICA, perteneciente a la Facultad de Ciencias Agrarias, de la Universidad de Antioquia, Medellín-Colombia, durante el mes de julio del 2013.

El estudio se realizó mediante la técnica de producción de gas in vitro (Menke y Steingass, 1988; Theodorou et al., 1994); se utilizó como sustrato de fermentación, forrajes y sus combinaciones, más la adición de concentrado, propios de la base alimenticia 
de ganaderías que pastorean en solo gramíneas de Estrella (C. plectostachyus) y/o Guinea (M. maximus cv. Tanzania), y en sistemas silvopastoriles intensivos (SSPi) con leucaena (L. leucocephala), con una proporción de gramínea-leucaena 80:20 y de forrajeconcentrado 70:30.

Se aplicaron los siguientes tratamientos:

1. Pasto Estrella 70\% + concentrado 30\% (EC).

2. Pasto Guinea $70 \%$ + concentrado $30 \%$ (GC).

3. Pasto Estrella 35\%+ Guinea 35\% + concentrado $30 \%$ (EGC).
4. Pasto Estrella 56\% + leucaena $14 \%$ + concentrado $30 \%$ (ELC).

5. Pasto Guinea $56 \%$ + leucaena $14 \%$ + concentrado $30 \%$ (GLC).

6. Pasto Estrella 28\%+ Guinea 28\% + leucaena 14\% + concentrado $30 \%$ (EGLC).

7. Leucaena $70 \%+$ concentrado $30 \%$ (LC).

La composición nutricional y el perfil de ácidos grasos de los tratamientos utilizados, se presenta en el Cuadro 1.

Las muestras de forraje y de concentrado empleadas, provenían de una sola finca manejada

Cuadro 1. Composición nutricional y perfil de ácidos grasos de los forrajes de pasto Estrella (C. plectostachyus), Guinea (M. maximus $c v$. Tanzania) y Leucaena (L. leucocephala) y sus combinaciones más adición de concentrado, utilizados en la evaluación in vitro, antes de la incubación de las dietas por veinticuatro horas. Medellín, Colombia. Julio, 2013.

Table 1. Nutritional composition and fatty acid profile from forages of Estrella (C. plectostachyus), Guinea (M. maximus cv. Tanzania), and Leucaena (L. leucocephala) grasses and their combinations plus concentrate addition, used in the in vitro evaluation, before incubation of diets for twenty four hours. Medellin, Colombia. July, 2013.

\begin{tabular}{lccccccc}
\hline & \multicolumn{7}{c}{ Tratamientos } \\
\cline { 2 - 8 } Variable & EC & GC & EGC & ELC & GLC & EGLC & LC \\
\cline { 2 - 8 } & $\mathrm{n}=3$ & $\mathrm{n}=3$ & $\mathrm{n}=3$ & $\mathrm{n}=3$ & $\mathrm{n}=3$ & $\mathrm{n}=3$ & $\mathrm{n}=3$ \\
\hline \% Grasa & 3,3 & 3,0 & 3,2 & 3,2 & 3,2 & 3,2 & 3,4 \\
\% Proteína & 13,0 & 15,1 & 13,8 & 15,1 & 16,7 & 15,6 & 22,8 \\
\% FDN & 62,7 & 55,1 & 57,9 & 56,8 & 50,5 & 53,7 & 34,8 \\
\% FDA & 27,4 & 25,5 & 26,6 & 24,5 & 23,3 & 23,7 & 12,2 \\
\% Cenizas & 9,2 & 12,2 & 10,6 & 9,4 & 12,7 & 10,0 & 7,5 \\
\hline & & \multicolumn{7}{c}{ Ácidos grasos (AG) } & g de AG/100 g de AG totales & & \\
\hline C12 & 1,13 & 1,25 & 1,10 & 0,88 & 0,98 & 1,06 & 0,86 \\
C14 & 1,21 & 1,31 & 1,17 & 1,02 & 1,12 & 1,15 & 0,96 \\
C16+c15:1c10 & 31,33 & 33,06 & 31,15 & 30,50 & 31,99 & 31,54 & 30,05 \\
C18 & 6,71 & 6,82 & 6,81 & 7,05 & 6,87 & 7,04 & 7,71 \\
C18:1t11 & 1,02 & 0,98 & 1,07 & 1,09 & 0,93 & 0,96 & 0,88 \\
C18:1c9 & 17,64 & 16,76 & 17,41 & 17,64 & 16,95 & 17,38 & 15,20 \\
C18:2c9,12 & 21,89 & 21,93 & 22,03 & 22,78 & 22,93 & 22,55 & 21,00 \\
C18:3c9,12,15 & 9,47 & 10,76 & 9,79 & 11,17 & 11,67 & 10,99 & 16,91 \\
Sumatorias & & & & & & &
\end{tabular}

EC: Estrella 70\% + concentrado 30\%; GC: Guinea 70\% + concentrado 30\%; EGC: Estrella 35\% + Guinea 35\% + concentrado 30\%; ELC: Estrella 56\% + leucaena 14\% + concentrado 30 \%; GLC: Guinea 56\% + leucaena 14\% + concentrado 30\%; EGLC: Estrella 28\% + Guinea 28\%+ leucaena 14\% + concentrado 30\%; LC: leucaena 70\% + concentrado 30\%; FDN: fibra insoluble en detergente neutro, FDA: fibra insoluble en detergente ácido, AGMI: ácidos grasos monoinsaturados, AGPI: ácidos grasos poli insaturados / EC: Estrella $70 \%$ + concentrate 30\%; GC: Guinea 70\% + concentrate 30\%; EGC: Estrella 35\% + Guinea 35\% + concentrate 30\%; ELC: Estrella $56 \%$ + leucaena 14\% + concentrate 30\%; GLC: Guinea 56\% + leucaena 14\% + concentrate 30\%; EGLC: Estrella 28\% + Guinea 28\% + leucaena14\% + concentrate 30\%; LC: leucaena 70\% + concentrate 30\%; FDN (NDF): neutral detergent fiber, FDA (ADF): acid detergent fiber, AGMI (MUFA): monounsaturated fatty acids, AGPI (PUFA):polyunsaturated fatty acids. 
bajo sistema silvopastoril intensivo, representativa de los sistemas evaluados. Los forrajes tenían una edad de rebrote de cuarenta días y su cosecha se realizó durante la época de lluvias. Los forrajes se colocaron en estufa a $60{ }^{\circ} \mathrm{C}$ durante 48 horas y luego fueron molidos, al igual que el concentrado, utilizando una criba de $1 \mathrm{~mm}$.

Se tomó una muestra de alimento de cada tratamiento para determinar la composición química y el perfil de ácidos grasos. La composición química se realizó mediante las técnicas analíticas convencionales de la AOAC (1999) (materia seca método ID 934.01, cenizas método ID 942.05 , proteína bruta método ID 984.13, grasa y fibra detergente ácido método ID 973.18) y los descritos por Van Soest et al. (1991) para los análisis de fibra detergente neutro y fibra detergente ácido.

El perfil de ácidos grasos se realizó mediante el método de cromatografía de gases acoplado a espectrometría de masas, siguiendo la metodología propuesta por Tequin-Ocampo (2014), tanto para la extracción-derivatización como para el análisis cromatográfico en sí mismo; para esto, las muestras de alimento fueron liofilizadas. Seguidamente se realizó la derivatización de los ácidos grasos siguiendo el protocolo de esterificación, que consiste en pesar 50 mg de alimento y depositarlos en viales de reacción ámbar de $4 \mathrm{ml}$ con tapas de sílica, adicionar 300 ppm de estándar interno C19 y $1 \mathrm{ml}$ de metóxido de sodio $0,5 \mathrm{~N}$ en metanol, mezclar en vórtex durante tres minutos, calentar durante diez minutos a $50{ }^{\circ} \mathrm{C}$, sacar y mezclar, adicionar $1 \mathrm{ml}$ de $\mathrm{HCl} 0,5 \mathrm{~N}$ en metanol y mezclar en vórtex durante tres minutos, calentar durante diez minutos a $50{ }^{\circ} \mathrm{C}$, sacar y mezclar, enfriar a temperatura ambiente, adicionar $1 \mathrm{ml}$ de hexano y tapar, mezclar en vortex por dos minutos y finalmente, transferir con pipeta Pasteur la capa superior a viales de $1,5 \mathrm{ml}$ para posterior análisis cromatográfico. Se utilizó un cromatógrafo de gases acoplado a espectrómetro de masas, con automuestreador. Las condiciones cromatográficas fueron las siguientes; fase móvil: gas transportador helio, flujo de columna $1 \mathrm{ml} / \mathrm{min}$, velocidad lineal $26 \mathrm{~cm} / \mathrm{seg}$; inyector: temperatura $220{ }^{\circ} \mathrm{C}$, volumen $0,2 \mathrm{ul}$, modo Splitless; columna: modelo CP - Sil - 88, longitud $100 \mathrm{~m}$, diámetro interno $0,25 \mathrm{~mm}$, espesor de la película $0,2 \mathrm{ul}$; rampa de temperatura: temperatura $150{ }^{\circ} \mathrm{C}$, tiempo de calentamiento tres minutos, rata $15^{\circ} \mathrm{C} / \mathrm{min}$; detector: temperatura $250{ }^{\circ} \mathrm{C}$, flujo de $\mathrm{N} 210 \mathrm{ml} / \mathrm{min}$. Los ácidos grasos fueron separados e identificados por comparación de los tiempos de retención con sus respectivos estándares; se cuantificaron utilizando la curva de calibración de los estándares de ALC y sus isómeros, de ATV y los demás ácidos grasos. Se utilizó como estándar interno ácido nonadecanoico (C19:0). El porcentaje de cada AG fue calculado a partir de su concentración (ppm), determinada por cromatografía (Tequin-Ocampo, 2014).

La solución tampón se preparó un día antes del inicio del ensayo, de acuerdo con las recomendaciones de McDougall (1948): 9,8 g/l de $\mathrm{NaHCO}_{3}, 4,65 \mathrm{~g} / \mathrm{l} \mathrm{de}$ $\mathrm{Na}_{2} \mathrm{HPO}_{4} \cdot 7 \mathrm{H}_{2} \mathrm{O}, 0,57 \mathrm{~g} / \mathrm{l}$ de $\mathrm{KCl}, 0,47 \mathrm{~g} / 1 \mathrm{NaCl}, 0,12$ $\mathrm{g} / \mathrm{l} \mathrm{de} \mathrm{MgSO}_{4} \cdot 7 \mathrm{H}_{2} \mathrm{O}, 0,05 \mathrm{~g} / \mathrm{l} \mathrm{de} \mathrm{CaCl}_{2}$. Estos reactivos fueron disueltos totalmente en agua destilada y la solución fue saturada con $\mathrm{CO}_{2}$ y almacenada a $39^{\circ} \mathrm{C}$.

En cada tratamiento se usaron tres inóculos, procedentes de tres novillos que consumían pastos Cynodon plectostachyus, Panicum maximum, Brachiaria mutica y Dichantium aristatum Benth. La colecta del líquido ruminal se hizo inmediatamente después del sacrificio, se filtró en paños de algodón y se almacenó en termos pre-calentados con agua a $40^{\circ} \mathrm{C}$. En el laboratorio, el líquido ruminal de cada animal se filtró nuevamente y fue transferido a tres erlenmeyer (uno por cada animal), los cuales fueron saturados con $\mathrm{CO}_{2}$ y mantenidos en estufa a $39^{\circ} \mathrm{C}$, durante el tiempo que demoró la inoculación.

\section{Determinación de la cinética de fermentación y degradación in vitro}

La cinética de fermentación se determinó mediante la técnica de producción de gas in vitro (Menke y Steingass, 1988; Theodorouet al., 1994) modificada por Posada et al. (2006). Se utilizaron botellas de 100 $\mathrm{ml}$ de capacidad, en las que se colocó $0,5 \mathrm{~g}$ de sustrato de fermentación, $5 \mathrm{ml}$ de líquido ruminal y $45 \mathrm{ml}$ de medio de cultivo, bajo un flujo de $\mathrm{CO}_{2}$. Las botellas se cerraron con tapones de caucho y se pre-cintaron con cápsulas de aluminio. Luego se agitaron y se colocaron dentro de una estufa de cultivo que se mantuvo a $39^{\circ} \mathrm{C}$.

Adicionalmente, se utilizaron dos frascos/inóculo, que contenían medio de cultivo e inóculo, pero no sustrato, los cuales fueron usados como blancos para corregir la presión generada por la utilización de $\mathrm{CO}_{2}$, y la presión producida por la fermentación de los microorganismos presentes en el líquido ruminal. 
Al cabo de 2, 4, 6, 8,10,12,15, 24, 30, 36, 48, 72 y 96 horas de incubación, se midió la producción de gas a partir del aumento de presión en el espacio de la cabeza de los viales, utilizando un transductor digital, acoplado a una aguja que se introducía a través de la tapa de caucho de los frascos. La presión se midió en libras por pulgada cuadrada (PSI). Para transformar los datos de presión (PSI) (X) en volumen de gas (ml) $(\mathrm{Y})$, se utilizó la ecuación $\mathrm{Y}=-0,1375+\left(5,1385^{*} \mathrm{X}\right)+$ $\left(0,0777 * X^{2}\right)$, propuesta por Posada et al. (2006).

Al finalizar la incubación, el contenido de las botellas se filtró usando crisoles (poro número 1) de peso conocido; se utilizó una bomba de vacío. El residuo recuperado se secó en horno $\left(65^{\circ} \mathrm{C}\right.$ por $\left.48 \mathrm{~h}\right)$, luego se pesó y se usó para calcular por gravimetría la digestibilidad de la MS (García-González et al., 2008).

Para establecer la relación entre la cantidad de sustrato degradado $(\mathrm{mg})$ y el volumen de gas producido (ml) se calculó el factor de partición (FP), que es considerado como un factor de eficiencia microbiana (Duque et al., 2009).

\section{Determinación de metano, $\mathrm{pH}$,ácidos grasos volátiles y perfil de ácidos grasos (ALC, ATV y AGCL)}

Para estas determinaciones se utilizaron botellas de fermentación similares a las descritas, preparadas de manera simultánea y de la misma forma; pero en este caso, la fermentación solo se adelantó por un periodo total de veinticuatro horas. Al cabo de este tiempo, se midió el volumen de gas acumulado en el espacio de cabeza de la botella, utilizando un transductor digital, y mediante una jeringa se tomó una muestra de gas presente en la botella y se colocó dentro de un tubo de ensayo $(10 \mathrm{ml})$ con vacío. Posteriormente, en esta muestra de gas, se determinó la concentración de metano mediante cromatografía de gases; para ello, se tomaron $200 \mu 1$ de muestra, los cuales se inyectaron manualmente, con una jeringa de $1 \mathrm{ml}$, en un cromatógrafo equipado con detector de ionización de llama (FID) y una columna empacada, modelo GS-AL/KCl, de $50 \mathrm{~m}$ de largo, $0,53 \mathrm{~mm}$ de diámetro, con fase móvil de nitrógeno al 99,995\% de pureza, flujo constante de $1 \mathrm{ml} / \mathrm{min}$ y programación del horno con isoterma a $80{ }^{\circ} \mathrm{C}$, durante cinco minutos, seguido de una temperatura post corrida de $100{ }^{\circ} \mathrm{C}$ durante un minuto. El contenido de metano se determinó mediante la generación de un curva de calibración, obtenida diluyendo un estándar de metano de alta pureza $(99,99 \%)$ con $\mathrm{CO}_{2}$, procedimiento que se realizó siguiendo los lineamientos de López y Newbold (2007).

La producción de metano $(\mathrm{ml})$ fue calculada a partir del volumen total de gas $(\mathrm{ml})$ y la concentración de metano. Esta se expresó por gramo de materia seca incubada (MSi). Del mismo modo, se hizo la determinación de la concentración de metano a 48 horas, la muestra provenía de las botellas que se incubaron por 96 horas; para esto, el gas que produjo cada botella a las 2, 4, 6, 8, 10, 12, 15, 24, 30, 36 y 48 horas de incubación, se colectó en la respectiva medición de producción de gas, con una jeringa conectada, junto con el transductor digital, a una válvula de tres salidas. La primera salida fue conectada a una aguja que se insertaba en el interior de la botella incubada, la segunda al trasductor de presión y la tercera a la jeringa plástica que colectaba el gas. El gas colectado fue acumulado en una bolsa herméticamente cerrada, utilizando una por cada botella, posteriormente se tomó una muestra del gas presente en esta y se colocó dentro de un tubo de ensayo $(10 \mathrm{ml})$ con vacío.

Luego de abrir las botellas incubadas por veinticuatro horas, se midió el $\mathrm{pH}$ con $\mathrm{pH}$-metro digital; se tomó una muestra de líquido sobrenadante de cada botella $(0,8 \mathrm{ml})$, para hacer la determinación de ácidos grasos volátiles (AGV); esta muestra fue congelada inmediatamente. Posteriormente, se preparó para análisis de cromatografía de gases, para esto la muestra fue descongelada y agitada. Se tomaron 800 $\mu 1$ de muestra y se colocaron en un tubo eppendorf, se adicionaron $500 \mu \mathrm{l}$ de una solución con $20 \mathrm{~g} / \mathrm{l}$ de ácido metafosfórico y $4 \mathrm{~g} / \mathrm{l}$ de ácido crotónico (usado como estándar interno) en ácido clorhídrico 0,5 N, se tapó y dejó por dos horas, al cabo de las cuales se centrifugó a $13000 \mathrm{rpm}$ durante quince minutos. Seguidamente se tomó $1 \mathrm{ml}$ de sobrenadante y se colocó en viales de 1,5 $\mathrm{ml}$, los cuales fueron colocados en el automuestreador del cromatógrafo. Se usó un cromatógrafo equipado con detector de ionización de llama, con una columna capilar TR-FFAP de $30 \mathrm{~m} \times 0,53 \mathrm{~mm} \times 1 \mathrm{~m}$. Las condiciones de temperatura fueron $50{ }^{\circ} \mathrm{C}$ iniciales en la columna por cinco minutos, $225^{\circ} \mathrm{C}$ por diez minutos con un gradiente de $5{ }^{\circ} \mathrm{C}$ por minuto. El gas portador fue nitrógeno, con un flujo de $1 \mathrm{ml} /$ minuto. El volumen de inyección de 0,4 $\mu 1$ a una temperatura de $225^{\circ} \mathrm{C}$ en modo split 1:50.

La concentración de AGV (mmol/l) fue calculada a partir de la concentración (ppm) determinada por 
cromatografía, asumiendo una masa molar de $60,05 \mathrm{~g} / \mathrm{mol}$ para el ácido acético, 74,08 g/mol para propiónico, 88,11 $\mathrm{g} / \mathrm{mol}$ para ácido butírico e isobutírico y 102,13 g/mol para los ácidos pentanóico e isopentanóico, seguidamente se calculó la proporción molar de cada AGV.

El líquido que quedó en las botellas, se usó para el análisis de AG, para esto, se almacenó a $-20{ }^{\circ} \mathrm{C}$ hasta el momento de la extracción de los lípidos y su análisis por cromatografía de gases, siguiendo el procedimiento descrito anteriormente para AG de los alimentos.

\section{Estimación de la biohidrogenación}

La biohidrogenación (BH) se estimó como la desaparición de ácido oleico (C18: 1c9), linoleico (C18: 2c9,12) y linolénico $(\mathrm{C} 18: 3 \mathrm{c} 9,12,15)$ contenidos en las dietas incubadas y después de 24 h de incubación, suponiendo que la desaparición de estos ácidos grasos se debió a la biohidrogenación. Cada ácido graso se expresó como una proporción del total de estos AG C18 (Amaro et al., 2012). El porcentaje de cada AG después de la fermentación fue corregido por su blanco, para esto se le restó el respectivo porcentaje de AG presente en el blanco y luego se estableció la relación, aplicando la siguiente fórmula descrita por Amaro et al. (2012):

Biohidrogenación=1-(AG C18 individual contenido en la fermentación después de $24 \mathrm{~h}$ de incubación/ total de AG C18 en la fermentación después de 24 h de incubación)/(AG C18 individual contenido en la dieta/ total de AG $\mathrm{C} 18$ en la dieta).

\section{Análisis estadístico}

La cinética de producción de gas fue ajustada al modelo de France et al. (2000); correspondiente a $G$ $=A[1-\exp -c(t-L)]$, donde $\mathrm{G}(\mathrm{ml} / \mathrm{g})$ es el volumen de gas acumulado en el tiempo $(\mathrm{t}) ; \mathrm{A}(\mathrm{ml} / \mathrm{g})$ es el volumen de gas correspondiente a la digestión completa del sustrato (asíntota); C (\%/hora) es la tasa constante de producción de gas y L (horas) es el tiempo de colonización. El ajuste de los datos al modelo y las estimativas de los parámetros se realizaron a través de PROC NLIN de SAS (2004).

El perfil de ácidos grasos (ALC, ATV, AGCL), biohidrogenación, parámetros de producción de gas, FP, digestibilidad de la MS, producción de metano,
$\mathrm{pH}$ y los AGV, se analizaron mediante ANOVA en un diseño completamente al azar (CAA). El efecto fijo en el modelo correspondió al tratamiento experimental y el efecto aleatorio al inóculo ruminal. La diferencia entre promedios se analizó mediante prueba de Tukey, con nivel de significancia del 5\%, utilizando PROC GLM de SAS (2004).

Adicionalmente, para dilucidar el efecto de la leucaena sobre la composición de AG en la fermentación, se realizaron contrastes ortogonales utilizando PROC GLM de SAS (2004).

\section{RESULTADOS Y DISCUSIÓN}

\section{Ácido linoleico conjugado, trasvaccénico y otros ácidos grasos de cadena larga después de la fermentación ruminal}

La proporción de ácidos grasos después de la fermentación ruminal, se presenta en el Cuadro 2. No se presentó efecto significativo del tratamiento $(\mathrm{p}>0,05)$ sobre el contenido de ALC c9t11 (ácido ruménico). Igualmente, la comparación de los tratamientos con leucaena vs sin leucaena (ELC, GLC, EGLC vs EC,GC,EGC) (Cuadro 3) no fue significativa $(p>0,05)$, indicando que la inclusión de leucaena no tuvo efecto sobre este AG. No obstante, sí hubo un efecto significativo del tratamiento $(\mathrm{p}<0,05)$ sobre el contenido de ATV (C18:1 t11), linoleico (C18:2 c9,12), linolénico (C18:3 c9,12,15) y esteárico (C18:0). El tratamiento que incluía solo leucaena como forraje (LC) presentó la mayor proporción de ATV (C18:1 t11) respecto a los tratamientos GC y EGC, de linoleico $(\mathrm{C} 18: 2 \mathrm{c} 9,12)$ respecto a $\mathrm{GC}$, de linolénico $(\mathrm{C} 18: 3 \mathrm{c} 9,12,15)$ respecto a $\mathrm{EC}$, GC, y de esteárico (C18:0) con respecto a EGC. Asimismo, las comparaciones entre los tratamientos que incluían leucaena respecto a los que no la incluían (ELC,GLC,EGLC) vs (EC,GC,EGC) (Cuadro 3), mostraron que la inclusión de leucaena aumentó el porcentaje de estos ácidos grasos y hubo una tendencia $(\mathrm{p}=0,08)$ a incrementar ácido linolénico. Al comparar el comportamiento de las gramíneas EC contra GC, no se presentaron diferencias significativas entre ellas ( $>00,05)$, en el contenido de ATV, linoleico, linolénico y esteárico, cuando se encontraban solas o en mezcla con leucaena. 
Cuadro 2. Ácidos grasos ( $\mathrm{g}$ de $\mathrm{AG} / 100 \mathrm{~g}$ de $\mathrm{AG}$ totales) obtenidos en la fermentación ruminal in vitro de los forrajes de silvopasturas intensivas con leucaena y sus combinaciones más adición de concentrado, después de la incubación por veinticuatro horas. Medellín, Colombia. Julio del 2013.

Table 2. Fatty acids ( $g$ of FA/100 g of total FA) obtained in the in vitro ruminal fermentation of forages in intensive silvopastures with Leucaena and their combinations plus concentrate addition, after incubation for twenty four hours. Medellin, Colombia. July 2013.

\begin{tabular}{|c|c|c|c|c|c|c|c|c|c|c|c|c|c|c|c|}
\hline \multirow[t]{2}{*}{ Ácidos grasos (AG) } & \multicolumn{15}{|c|}{ Tratamientos } \\
\hline & EC & & GC & & EGC & & ELC & & GLC & & EGLC & & LC & & Valor $p$ \\
\hline C6:0 & 1,22 & & 1,06 & & 1,07 & & 1,28 & & 1,13 & & 1,32 & & 1,41 & & 0,1300 \\
\hline C8:0 & 0,22 & & 0,21 & & 0,21 & & 0,23 & & 0,23 & & 0,25 & & 0,26 & & 0,7114 \\
\hline C10:0 & 0,11 & & 0,11 & & 0,11 & & 0,11 & & 0,12 & & 0,12 & & 0,12 & & 0,3476 \\
\hline C11:0 & 0,10 & & 0,11 & & 0,11 & & 0,12 & & 0,13 & & 0,13 & & 0,12 & & 0,4222 \\
\hline $\mathrm{C} 12: 0$ & 0,63 & & 0,64 & & 0,64 & & 0,64 & & 0,70 & & 0,68 & & 0,64 & & 0,3805 \\
\hline C13:0 & 0,15 & & 0,14 & & 0,15 & & 0,17 & & 0,16 & & 0,19 & & 0,17 & & 0,5678 \\
\hline $\mathrm{C} 14: 0$ & 2,36 & & 2,35 & & 2,35 & & 2,41 & & 2,60 & & 2,51 & & 2,27 & & 0,4455 \\
\hline $\mathrm{C} 15+\mathrm{C} 14: 1 \mathrm{c} 9$ & 2,92 & & 2,88 & & 2,85 & & 3,00 & & 3,16 & & 3,12 & & 2,68 & & 0,1030 \\
\hline C16 & 24,51 & & 23,86 & & 23,58 & & 25,31 & & 26,50 & & 25,63 & & 25,62 & & 0,1734 \\
\hline $\mathrm{C} 16: 1 \mathrm{c} 9$ & 0,36 & & 0,34 & & 0,52 & & 0,39 & & 0,39 & & 0,40 & & 0,42 & & 0,3447 \\
\hline C17:0 & 1,01 & & 1,04 & & 1,00 & & 1,04 & & 1,15 & & 1,11 & & 1,03 & & 0,1113 \\
\hline $\mathrm{C} 17: 1 \mathrm{c} 10$ & 5,72 & & 9,51 & & 7,34 & & 4,07 & & 0,29 & & 2,21 & & 2,22 & & 0,0611 \\
\hline C18:0 & 26,29 & $a b$ & 25,62 & $a b$ & 24,36 & $\mathrm{~b}$ & 26,64 & $\mathrm{ab}$ & 27,70 & $\mathrm{a}$ & 27,76 & $\mathrm{a}$ & 27,82 & $\mathrm{a}$ & 0,0136 \\
\hline C18:1c9 & 4,53 & & 4,08 & & 4,60 & & 4,96 & & 5,01 & & 4,70 & & 4,82 & & 0,2285 \\
\hline C18:1t9 & 4,53 & & 4,25 & & 6,23 & & 2,62 & & 2,87 & & 2,89 & & 1,15 & & 0,7687 \\
\hline C18:1t11 & 14,18 & $a b$ & 13,53 & $\mathrm{~b}$ & 13,71 & $\mathrm{~b}$ & 15,07 & $a b$ & 15,37 & $a b$ & 15,12 & $a b$ & 16,65 & $\mathrm{a}$ & 0,0155 \\
\hline $\mathrm{C} 18: 2 \mathrm{c} 9,12$ & 2,14 & $\mathrm{bc}$ & 1,89 & $\mathrm{c}$ & 2,18 & $\mathrm{bc}$ & 2,28 & $a b c$ & 2,43 & $a b$ & 2,23 & $\mathrm{bc}$ & 2,73 & $\mathrm{a}$ & 0,0013 \\
\hline $\mathrm{C} 18: 2 \mathrm{c} 9 \mathrm{t} 11$ & 0,79 & & 0,71 & & 0,77 & & 0,95 & & 0,96 & & 0,92 & & 0,89 & & 0,8193 \\
\hline $\mathrm{C} 18: 2 \mathrm{t} 9,12$ & 0,26 & & 0,26 & & 0,28 & & 0,33 & & 0,29 & & 0,34 & & 0,33 & & 0,4098 \\
\hline C18:2c10t12 & 0,30 & & 0,28 & & 0,30 & & 0,35 & & 0,33 & & 0,38 & & 0,34 & & 0,4239 \\
\hline $\mathrm{C} 18: 2 \mathrm{t} 10 \mathrm{c} 12$ & 0,53 & & 0,48 & & 0,52 & & 0,53 & & 0,61 & & 0,62 & & 0,71 & & 0,1210 \\
\hline C18:2MX & 0,25 & & 0,17 & & 0,24 & & 0,23 & & 0,26 & & 0,23 & & 0,22 & & 0,2706 \\
\hline $\mathrm{C} 18: 3 \mathrm{c} 6,9,12$ & 0,32 & & 0,33 & & 0,29 & & 0,35 & & 0,38 & & 0,32 & & 0,35 & & 0,8588 \\
\hline $\mathrm{C} 18: 3 \mathrm{c} 9,12,15$ & 1,55 & $\mathrm{~b}$ & 1,74 & $\mathrm{~b}$ & 1,90 & $a b$ & 1,78 & $\mathrm{ab}$ & 2,16 & $a b$ & 1,82 & $a b$ & 2,38 & $\mathrm{a}$ & 0,0076 \\
\hline C20:0 & 0,96 & & 0,92 & & 0,93 & & 1,01 & & 1,05 & & 1,03 & & 1,07 & & 0,1989 \\
\hline $\mathrm{C} 20: 1 \mathrm{c} 11$ & 0,30 & & 0,27 & & 0,30 & & 0,31 & & 0,30 & & 0,31 & & 0,31 & & 0,9688 \\
\hline $\mathrm{C} 21: 0$ & 0,26 & & 0,21 & & & & 0,25 & & & & 0,26 & & & & 0,6874 \\
\hline $\mathrm{C} 22: 0$ & 0,74 & & 0,68 & & 0,71 & & 0,76 & & 0,77 & & 0,79 & & 0,75 & & 0,1649 \\
\hline $\mathrm{C} 23+\mathrm{C} 20: 3 \mathrm{c} 11,14,17$ & 0,80 & & 0,74 & & 0,76 & & 0,81 & & 0,83 & & 0,85 & & 0,75 & & 0,2181 \\
\hline $\mathrm{C} 24: 0$ & 1,23 & & 1,08 & & 1,13 & & 1,22 & & 1,22 & & 1,27 & & 1,20 & & 0,0188 \\
\hline $\mathrm{C} 24: 1 \mathrm{c} 15$ & 0,6 & & 0,54 & & 0,57 & & 0,67 & & 0,6 & & 0,68 & & 0,58 & & 0,4955 \\
\hline
\end{tabular}

EC: Estrella 70\% + concentrado 30\%; GC: Guinea 70\% + concentrado 30\%; EGC: Estrella 35\%+ Guinea 35\% + concentrado 30\%; ELC: Estrella 56\% + leucaena 14\% + concentrado 30\%; GLC: Guinea 56\% + Leucaena 14\% + concentrado 30\%; EGLC: Estrella 28\% + Guinea 28\% + leucaena 14\% + concentrado 30\%; LC: leucaena 70\% + concentrado 30\% / EC: Estrella $70 \%$ + concentrate 30\%; GC: Guinea 70\% + concentrate 30\%; EGC: Estrella 35\% + Guinea 35\% + concentrate 30\%; ELC: Estrella $56 \%$ + Leucaena 14\% + concentrate 30\%; GLC: Guinea 56\% + leucaena 14\% + concentrate 30\%; EGLC: Estrella 28\% + Guinea $28 \%$ + leucaena 14\% + concentrate 30\%; LC: leucaena70\% + concentrate $30 \%$.

Valores con letras diferentes en la misma fila difieren significativamente entre tratamientos $(\mathrm{p}<0,05) /$ Values with different letters in the same row differ significantly between treatments $(p<0.05)$.

Por otra parte, la inclusión de $14 \%$ de leucaena en la mezcla con gramínea no afectó la biohidrogenación de los ácidos oleico, linoleico y linolénico $(\mathrm{p}>0,05)$.
La biohidrogenación del ácido oleico C18:1 c9 fue de 76 a 92\%, la del ácido linoleico C18:2 c9,12 de 47 a $55 \%$ y la del ácido linolénico C18:3 c9,12,15 de 18 a 
Cuadro 3. Ácidos grasos (g de AG/100 g de AG Totales) obtenidos en la fermentación ruminal in vitro de los forrajes y sus combinaciones más adición de concentrado, después de la incubación por veinticuatro horas. Medellín, Colombia. Julio, 2013.

Table 3. Fatty acids ( $\mathrm{g}$ of FA/100 $\mathrm{g}$ of total FA) obtained in the in vitro ruminal fermentation of forages and their combinations plus concentrate addition, after incubation for twenty four hours. Medellin, Colombia. July, 2013.

\begin{tabular}{|c|c|c|c|c|c|}
\hline \multirow{3}{*}{$\frac{\text { Ácidos grasos (AG) }}{\text { C6:0 }}$} & \multicolumn{5}{|c|}{ Contrastes } \\
\hline & \multicolumn{2}{|c|}{ EC, GC, EGC } & \multicolumn{2}{|c|}{ ELC, GLC, EGLC } & \multirow{2}{*}{$\frac{\text { Valor } \mathbf{P}}{0,0504}$} \\
\hline & 1,11 & $\mathrm{~b}$ & 1,24 & $\mathrm{a}$ & \\
\hline $\mathrm{C} 8: 0$ & 0,21 & & 0,23 & & 0,2534 \\
\hline C10:0 & 0,10 & $\mathrm{~b}$ & 0,11 & $\mathrm{a}$ & 0,0539 \\
\hline $\mathrm{C} 11: 0$ & 0,10 & $\mathrm{~b}$ & 0,12 & $\mathrm{a}$ & 0,0287 \\
\hline C12:0 & 0,63 & & 0,67 & & 0,1063 \\
\hline C13:0 & 0,14 & & 0,17 & & 0,1178 \\
\hline C14:0 & 2,35 & & 2,50 & & 0,1124 \\
\hline $\mathrm{C} 15+\mathrm{C} 14: 1 \mathrm{c} 9$ & 2,88 & $\mathrm{~b}$ & 3,09 & $\mathrm{a}$ & 0,0360 \\
\hline $\mathrm{C} 16$ & 23,98 & $\mathrm{~b}$ & 25,81 & $\mathrm{a}$ & 0,0130 \\
\hline C16:1c9 & 0,40 & & 0,39 & & 0,7311 \\
\hline $\mathrm{C} 17: 0$ & 1,01 & $\mathrm{~b}$ & 1,10 & $\mathrm{a}$ & 0,0168 \\
\hline $\mathrm{C} 17: 1 \mathrm{c} 10$ & 7,52 & $\mathrm{a}$ & 2,18 & $\mathrm{~b}$ & 0,0053 \\
\hline C18:0 & 25,42 & $\mathrm{~b}$ & 27,33 & $\mathrm{a}$ & 0,0024 \\
\hline C18:1c9 & 4,40 & $\mathrm{~b}$ & 4,89 & $\mathrm{a}$ & 0,0326 \\
\hline C18:1t9 & 5,00 & & 2,81 & & 0,2479 \\
\hline C18:1t11 & 13,80 & $\mathrm{~b}$ & 15,18 & $\mathrm{a}$ & 0,0078 \\
\hline $\mathrm{C} 18: 2 \mathrm{c} 9,12$ & 2,07 & $\mathrm{~b}$ & 2,31 & $\mathrm{a}$ & 0,0088 \\
\hline $\mathrm{C} 18: 2 \mathrm{c} 9 \mathrm{t} 11$ & 0,75 & & 0,94 & & 0,1356 \\
\hline $\mathrm{C} 18: 2 \mathrm{t} 9,12$ & 0,26 & $\mathrm{~b}$ & 0,32 & $\mathrm{a}$ & 0,0564 \\
\hline C18:2c10t12 & 0,29 & $\mathrm{~b}$ & 0,35 & $\mathrm{a}$ & 0,0497 \\
\hline $\mathrm{C} 18: 2 \mathrm{t} 10 \mathrm{c} 12$ & 0,50 & & 0,58 & & 0,0994 \\
\hline C18:2MX & 0,22 & & 0,23 & & 0,3998 \\
\hline $\mathrm{C} 18: 3 \mathrm{c} 6,9,12$ & 0,30 & & 0,35 & & 0,3489 \\
\hline $\mathrm{C} 18: 3 \mathrm{c} 9,12,15$ & 1,72 & & 1,91 & & 0,0858 \\
\hline C20:0 & 0,93 & $\mathrm{~b}$ & 1,02 & $\mathrm{a}$ & 0,0252 \\
\hline C20:1c11 & 0,28 & & 0,30 & & 0,5602 \\
\hline $\mathrm{C} 21: 0$ & 0,24 & & 0,25 & & 0,3762 \\
\hline $\mathrm{C} 22: 0$ & 0,70 & $\mathrm{~b}$ & 0,77 & a & 0,0110 \\
\hline $\mathrm{C} 23+\mathrm{C} 20: 3 \mathrm{c} 11,14,17$ & 0,76 & $\mathrm{~b}$ & 0,82 & a & 0,0378 \\
\hline $\mathrm{C} 24: 0$ & 1,14 & $\mathrm{a}$ & 0,23 & $\mathrm{~b}$ & 0,0420 \\
\hline $\mathrm{C} 24: 1 \mathrm{c} 15$ & 0,57 & & 0,64 & & 0,0921 \\
\hline
\end{tabular}

EC: Estrella 70\% + Concentrado 30\%; GC: Guinea $70 \%$ + Concentrado 30\%; EGC: Estrella $35 \%$ + Guinea 35\% + Concentrado 30\% ; ELC: Estrella 56\% + Leucaena 14\% + Concentrado 30\%; GLC: Guinea 56\% + Leucaena 14\% + Concentrado 30\%; EGLC: Estrella 28\% + Guinea $28 \%$ + Leucaena 14\% + Concentrado 30\% ; LC: Leucaena70\% + Concentrado 30\% / EC: Estrella 70\% + Concentrate 30\%; GC: Guinea 70\% + Concentrate 30\%; EGC: Estrella 35\% + Guinea 35\% + Concentrate 30\%; ELC: Estrella 56\% + Leucaena 14\% + Concentrate 30\%; GLC: Guinea 56\% + Leucaena 14\% + Concentrate 30\%; EGLC: Estrella 28\% + Guinea 28\% + Leucaena $14 \%$ + Concentrate 30\% ; L: Leucaena $70 \%$ + Concentrate $30 \%$.

Valores con letras diferentes en la misma fila difieren significativamente entre tratamientos $(p<0,05)$

/ Values with different letters in the same row differ significantly between treatments $(\mathrm{p}<0.05)$. 
39\% (Cuadro 4). El tratamiento LC que incluyó 70\% de leucaena como único forraje, tampoco afectó la biohidrogenación de estos tres ácidos grasos $(p>0,05)$.

La mayor proporción de ATV, linolénico y linoleico en la digesta de tratamientos que incorporaban leucaena (Cuadro 3), y el no efecto de la leucaena sobre la biohidrogenación del ácido oleico, linoleico y linolénico (Cuadro 4), sugieren que el aumento en ATV cuando se incluyó leucaena comparado a cuando no se incluyó, se debió a un aumento en sus precursores (linoleico y linolénico). Así, en los alimentos, el AG linoleico: aumentó 0,52\% en EGLC vs EGC, $0,89 \%$ en ELC vs EC y $1,0 \%$ en GLC vs GC; el AG linolénico: aumentó $0,91 \%$ en GLC vs GC, $1,19 \%$ en EGLC $v s$ EGC y $1,7 \%$ en ELC $v s$ EC. Por lo tanto, los microrganismos, al tener a disposición mayor cantidad de sustrato, incrementaron la producción de ATV, producto de la biohidrogenación incompleta de los AG insaturados con potencial para ir a tejidos. Lo que está de acuerdo con lo encontrado por otros autores, quienes han reportado que el mayor consumo de ácido linolénico y linoleico, y su posterior conversión en
ATV a nivel de rumen, aumenta los niveles de ALC c9t11 en leche (Griinari y Bauman, 1999; Chilliard et al., 2007).

A pesar de que se han reportado varios efectos adversos de ácidos grasos trans en la salud humana, también se ha mencionado que el efecto de los bio-trans (trans producidos en el rumen por microorganismos) no es el mismo que el de los trans-industriales, por el contrario, algunos de ellos, como el ALC c9t11, ha sido reportados con gran potencial para la salud humana. Asimismo, ATV (ácido graso trans importante en la grasa de rumiantes) ha tomado gran importancia, debido a que se ha encontrado que puede servir como un precursor para la síntesis de ALC c9t11 endógeno en los tejidos humanos (Ryhänen et al., 2005; Mosley et al., 2006).

El AG esteárico, también se aumentó en los tratamientos con leucaena, indicando que la inclusión de leucaena también aumentó el producto de la BH completa, esto debido a la mayor cantidad de precursores para la formación de ácido esteárico.

Varios estudios han relacionado una disminución en la $\mathrm{BH}$ con la inclusión de leucaena, que podría

Cuadro 4. Biohidrogenación obtenida en la fermentación ruminal in vitro de los ácidos grasos insaturados C18 de los forrajes de pasto Estrella (C. plectostachyus), Guinea (M. maximus cv. Tanzania) y Leucaena (L. leucocephala) y sus combinaciones más adición de concentrado, después de la incubación por veinticuatro horas. Medellín, Colombia. Julio del 2013.

Table 4. In vitro ruminal biohydrogenation of unsaturated $\mathrm{C} 18$ fatty acids from forages of Estrella $(C$. plectostachyus), Guinea (M. maximus cv. Tanzania) and Leucaena (L. leucocephala) grasses and their combinations plus concentrate addition, after incubation for twenty four hours. Medellin, Colombia. July 2013.

\begin{tabular}{lcccccccc}
\hline \multirow{2}{*}{ Ácidos grasos (AG) } & \multicolumn{9}{c}{ Tratamiento } & \multicolumn{2}{c}{ Valor P } \\
\cline { 2 - 9 } & EC & GC & EGC & ELC & GLC & EGLC & LC & \\
\hline C18:1c9 & 0,84 & 0,88 & 0,76 & 0,91 & 0,81 & 0,85 & 0,92 & 0,5427 \\
C18:2c9,12 & 0,50 & 0,55 & 0,52 & 0,51 & 0,50 & 0,51 & 0,47 & 0,4435 \\
C18:3c9,12,15 & 0,38 & 0,24 & 0,18 & 0,39 & 0,19 & 0,30 & 0,38 & 0,1644 \\
\hline
\end{tabular}

Biohidrogenación=1-(AG C18 individual contenido en la fermentación después de 24 h de incubación/total de AG C18 en la fermentación después de 24 h de incubación)/(AG C18 individual contenido en la dieta/ total de AG C18 en la dieta) / Biohydrogenation=1-(individual content of C18 FA during fermentation after $24 \mathrm{~h}$ of incubation/total content of C18 FA during fermentation after $24 \mathrm{~h}$ of incubation)/( individual content of $\mathrm{C} 18 \mathrm{FA}$ in the diet/total content of $\mathrm{C} 18 \mathrm{FA}$ in the diet).

EC: Estrella 70\% + concentrado 30\%; GC: Guinea 70\% + concentrado 30\%; EGC: Estrella 35\%+ Guinea $35 \%$ + concentrado 30\%; ELC: Estrella 56\% + leucaena 14\% + concentrado 30\%; GLC: Guinea 56\% + leucaena $14 \%$ + concentrado $30 \%$; EGLC: Estrella 28\% + Guinea 28\% + leucaena 14\% + concentrado 30\%; LC: leucaena 70\% + concentrado 30\% / EC: Estrella 70\% + concentrate 30\%; GC: Guinea 70\% + concentrate 30\%; EGC: Estrella 35\% + Guinea 35\% + concentrate 30\%; ELC: Estrella 56\% + leucaena 14\% + concentrate 30\%; GLC: Guinea 56\% + leucaena 14\% + concentrate 30\%; EGLC: Estrella 28\% + Guinea $28 \%$ + leucaena $14 \%$ + concentrate $30 \%$; LC: leucaena $70 \%$ + concentrate $30 \%$. 
deberse a su contenido de taninos (3,0 a 4,9\%) (García et al., 2008), los cuales son compuestos fenólicos que interfieren con los procesos digestivos por la unión de proteínas de la dieta y por la disminución de la actividad de algunos microoganismos ruminales (Makkar, 2003). Minieri et al. (2014), encontraron que dietas ricas en taninos redujeron la biohidrogenación en estudios in vitro. No obstante, otros reportes han sugerido que suplementando con alimentos ricos en taninos se puede alterar favorablemente la biohidrogenación ruminal de ácidos grasos insaturados, mejorando la acumulación de ATV y por lo tanto, el contenido de ALC c9t11 en leche o carne (Khiaosa-ard et al., 2009, Vasta et al., 2009). Se encontró mayor proporción de ATV en estudios in vitro, evaluando diferentes dosis de taninos (Carreño et al., 2014); sin embargo, estos resultados han sido logrados utilizando dosis que han sido consideradas como excesivas en taninos e imprácticas en condiciones de campo.

La leucaena utilizada en el presente estudio presentó 4,24\% de taninos totales (porcentaje de ácido tánico). De acuerdo con la determinación de taninos realizada por Sallam et al. (2010) y Soltan et al. (2013), el 66\% de taninos totales es TC; de acuerdo con esto, se estimó que la leucaena utilizada en el presente estudio contuvo $2,8 \%$ de TC, cantidad inferior a la reportada por García et al. (2008) de $3,66 \%$ y por Sallam et al. (2010) de 3,25\%. Por lo tanto, la inclusión de $14 \%$ de leucaena en las mezclas en estudio, contenían 5,93 g de ácido tánico/ $\mathrm{kg}$ de MS, que representó el 0,59\% de la dieta. En estudios in vitro, Minieri et al. (2014) reportaron una disminución en la $\mathrm{BH}$ de los ácidos linoleico y linolénico utilizando 22,3 g de ácido tánico/kg de MS de taninos de Quebracho. Asimismo, Khiaosa-Ard et al. (2009), reportaron una inhibición del paso final de la $\mathrm{BH}$ del ácido linolénico, utilizando 7,9\% de la MS de taninos condensados, y Carreño et al. (2014), utilizando 6 y $8 \%$ de la MS, cantidades superiores a la utilizada en el presente estudio.

La BH está fuertemente influenciada por metabolitos secundarios presentes en las plantas, que incluye polifenol oxidasa (PPO) y taninos (Lee et al., 2007; Cabiddu et al., 2010). Aunque hay poca información disponible sobre los efectos de los compuestos polifenólicos sobre la actividad de la linoleico isomerasa (LA-I) en el rumen (Cabiddu et al., 2009; 2010). Vasta et al. (2009) indicaron que los taninos no interfieren con LA-I, pero interfieren con la proliferación microbiana; así, los taninos no inhiben la actividad de las enzimas microbianas, pero sí cambian la composición de la población microbiana ruminal, situación que pudo no haberse presentado en este estudio, debido al bajo nivel de taninos empleado, lo que no afectó la $\mathrm{BH}$.

La utilización de leucaena en el presente trabajo, se realizó incorporando la cantidad de forraje representativo de dietas observadas en los animales en condiciones de campo; por lo tanto, los resultados encontrados in vitro, tienen gran potencial que deberían ser profundizados con más investigaciones, que permitan evaluar su efecto directamente en el animal. Estudios previos realizados por Mahecha et al. (2008) resaltaron la bondad del sistema silvopastoril leucaena-estrella-guinea para la producción de ALC c9t11 en leche; sin embargo, los efectos no pudieron ser atribuidos totalmente al sistema, porque el objetivo de la evaluación fue comparar diferentes dosis de grasa sobrepasante en animales pastoreando en el sistema silvopastoril y no se utilizó un testigo con solo pastura. Se han reportado porcentajes importantes de ácidos grasos poliinsaturados en el músculo de novillos pastoreando en sistemas silvopastoriles compuestos por L. leucocephala, P. maximum y C. plectostachyus (Rodríguez-Echevarría et al., 2013). De igual manera, se debería tener en cuenta la disponibilidad de forraje aportado por la leucaena en el sistema, que podría ser dependiente de la época climática, así como del manejo del pastoreo en el sistema, ya que esto podría afectar su porcentaje de inclusión por los animales en la dieta y por lo tanto, cambiar el efecto. Mahecha et al. (2000) reportaron una relación de hasta 71:29 (gramínea:leucaena), para algunos meses, en un sistema con aproximadamente cuatro años de establecido.

\section{Parámetros de fermentación y producción de metano}

La cinética de la fermentación, al igual que el FP, no se vieron afectados por el tratamiento $(p>0,05)$. El porcentaje de digestibilidad de la materia seca presentó diferencias significativas $(\mathrm{p}<0,05)$, siendo el tratamiento LC el que se comportó de manera diferente, presentando la menor digestibilidad; no obstante, la inclusión de la leucaena en la mezcla no afectó la digestibilidad de la materia seca, lo cual se considera benéfico (Cuadro 5). 
La investigación con leguminosas forrajeras, ha sugerido que los taninos condensados pueden ayudar a reducir la producción de gas ruminal (MonforteBriceño et al., 2005). Hess et al. (2003) informaron que la inclusión de leguminosas arbóreas con altos niveles de taninos como un suplemento de gramíneas con bajos niveles de proteína, disminuyó la digestibilidad de la materia seca. Sin embargo, en el presente estudio, un nivel de inclusión de 14\% de leucaena en la dieta, no afectó la producción de gas, ni la digestibilidad de la MS, solo se vio un efecto sobre la digestibilidad de la MS cuando la leucaena se incluyó como único forraje en un $70 \%$ de la dieta; aunque la digestibilidad de este tratamiento fue menor que en los otros $(64,77 \%$ vs 70,31 a $73,84 \%)$, su valor estuvo dentro del reportado (60-70\%) por Barros-Rodríguez et al. (2012). No obstante, en este tratamiento, no se presentaron diferencias para la producción de gas y cinética de fermentación, debido posiblemente a que se incluyó un $30 \%$ de concentrado en la dieta y a que

Cuadro 5. Cinética de fermentación, producción de metano, concentración y proporción de ácidos grasos volátiles (AGV) producto de la fermentación ruminal in vitro de los forrajes de pasto Estrella (C. plectostachyus), Guinea (M. maximus cv. Tanzania) y Leucaena (L. leucocephala) y sus combinaciones más adición de concentrado. Medellín, Colombia. Julio del 2013.

Table 5. Kinetics of fermentation, methane production, concentration and ratio of volatile fatty acids (VFA) produced by in vitro ruminal fermentation of forages from Estrella (C. plectostachyus), Guinea (M. maximus cv. Tanzania) and Leucaena $(L$. leucocephala) grasses and their combinations plus concentrate addition. Medellín, Colombia. Julio del 2013.

\begin{tabular}{|c|c|c|c|c|c|c|c|c|c|c|c|c|c|c|c|}
\hline \multirow[t]{2}{*}{ Variables } & \multicolumn{15}{|c|}{ Tratamientos } \\
\hline & EC & & GC & & EGC & & ELC & & GLC & & EGLC & & LC & & Valor $\mathbf{P}$ \\
\hline $\mathrm{A}(\mathrm{ml} / \mathrm{g}$ de $\mathrm{MS}$ inc $)$ & 289,08 & & 245,01 & & 261,64 & & 274,22 & & 260,92 & & 270,86 & & 266,45 & & 0,4233 \\
\hline c $(/ h)$ & 0,046 & & 0,050 & & 0,053 & & 0,050 & & 0,046 & & 0,050 & & 0,040 & & 0,4948 \\
\hline $\mathrm{L}(\mathrm{h})$ & 4,07 & & 4,86 & & 4,97 & & 4,37 & & 5,17 & & 4,64 & & 4,66 & & 0,9266 \\
\hline Digestibilidad (\%) & 73,84 & $\mathrm{a}$ & 71,32 & $a b$ & 73,66 & $\mathrm{a}$ & 72,48 & $a b$ & 70,31 & $\mathrm{~b}$ & 71,12 & $a b$ & 64,77 & $\mathrm{c}$ & $<0,0001$ \\
\hline $\begin{array}{l}\text { FP (mg MS Deg/ml } \\
\text { de gas) }\end{array}$ & 1,92 & & 2,30 & & 2,22 & & 2,03 & & 2,07 & & 1,99 & & 2,12 & & 0,3984 \\
\hline $\begin{array}{l}\text { Metano }(48 \mathrm{~h} \mathrm{ml} / \mathrm{g}) \\
\text { Ms Inc }\end{array}$ & 100,21 & & 74,53 & & 86,56 & & 86,97 & & 80,79 & & 93,52 & & 68,01 & & 0,8334 \\
\hline $\begin{array}{l}\text { Metano }(24 \mathrm{~h} \mathrm{ml} / \mathrm{g}) \\
\text { Ms Inc }\end{array}$ & 24,44 & & 22,82 & & 24,86 & & 23,56 & & 23,47 & & 24,09 & & 22,02 & & 0,9971 \\
\hline $\mathrm{pH}$ & 6,91 & & 6,84 & & 6,82 & & 6,88 & & 6,89 & & 6,83 & & 6,85 & & 0,5677 \\
\hline Total AGV (mmol/l) & 38,320 & & 37,100 & & 36,020 & & 37,410 & & 38,820 & & 38,580 & & 32,600 & & 0,7568 \\
\hline \multicolumn{16}{|c|}{ Proporción molar (\% molar) } \\
\hline Acético & 65,19 & $\mathrm{~b}$ & 65,66 & $\mathrm{~b}$ & 65,65 & $\mathrm{~b}$ & 65,99 & $\mathrm{~b}$ & 66,35 & $\mathrm{~b}$ & 66,34 & $\mathrm{~b}$ & 67,93 & a & $<0,0001$ \\
\hline Propiónico & 23,92 & a & 23,47 & $\mathrm{a}$ & 23,4 & $\mathrm{a}$ & 23,29 & $a b$ & 23,01 & $a b$ & 22,98 & $\mathrm{ab}$ & 21,53 & $\mathrm{~b}$ & 0,0145 \\
\hline Isobutírico & 1,00 & $a b$ & 1,09 & $\mathrm{a}$ & 1,06 & $\mathrm{a}$ & 0,99 & $a b$ & 1,04 & $a b$ & 1,01 & $\mathrm{ab}$ & 0,93 & $\mathrm{~b}$ & 0,0142 \\
\hline Butírico & 7,54 & & 7,37 & & 7,49 & & 7,41 & & 7,25 & & 7,33 & & 7,38 & & 0,9928 \\
\hline Isopentanóico & 1,28 & & 1,37 & & 1,34 & & 1,29 & & 1,35 & & 1,30 & & 1,27 & & 0,4934 \\
\hline Pentanóico & 1,03 & & 1,03 & & 1,03 & & 1,01 & & 0,99 & & 0,98 & & 0,93 & & 0,0708 \\
\hline acetato:propionato & 2,72 & $\mathrm{~b}$ & 2,79 & $\mathrm{~b}$ & 2,8 & $\mathrm{~b}$ & 2,83 & $\mathrm{~b}$ & 2,88 & $\mathrm{~b}$ & 2,88 & $\mathrm{~b}$ & 3,15 & $\mathrm{a}$ & 0,0015 \\
\hline
\end{tabular}

EC: Estrella 70\% + concentrado 30\%; GC: Guinea 70\% + concentrado 30\%; EGC: Estrella 35\%+ Guinea 35\% + concentrado 30\%; ELC: Estrella 56\% + leucaena 14\% + concentrado 30\%; GLC: Guinea 56\% + leucaena 14\% + concentrado 30\%; EGLC: Estrella $28 \%$ + Guinea $28 \%$ + leucaena $14 \%$ + concentrado 30\%; LC: leucaena 70\% + concentrado 30\%; A (ml/g): volumen de gas correspondiente a la digestión completa del sustrato (asíntota); C (\%/hora):tasa constante de producción de gas; L (horas): tiempo de colonización / EC: Estrella 70\% + concentrate 30\%; GC: Guinea 70\% + concentrate 30\%; EGC: Estrella 35\% + Guinea 35\% + concentrate 30\%; ELC: Estrella 56\% + leucaena 14\% + concentrate 30\%; GLC: Guinea 56\% + leucaena 14\% + concentrate 30\%; EGLC: Estrella 28\% + Guinea $28 \%$ + leucaena $14 \%$ + concentrate $30 \%$; LC: leucaena $70 \%$ + concentrate $30 \%$; A ( $\mathrm{ml} / \mathrm{g})$ : gas volumen from the complete digestión of the substrate (asymptote); $\mathrm{C}$ (\%/hour): constant gas production rate; $\mathrm{L}$ (hours): time of colonization.

Valores con letras diferentes en la misma fila difieren significativamente entre tratamientos $(\mathrm{p}<0,05) /$ Values with different letters in the same row differ significantly between treatments $(\mathrm{p}<0.05)$. 
la variedad de leucaena utilizada, L. leucocephala cv. Cunningham, se caracteriza por un bajo contenido de taninos condensados, mimosina y una elevada degradabilidad ruminal de las fracciones nutritivas (García et al., 2008), que no afectaron la fermentación microbiana. Igualmente, el FP utilizado como factor de eficiencia microbiana no se vio afectado. Se ha demostrado que los rumiantes pueden tolerar hasta $30 \%$ de leucaena en la dieta sin tener un impacto negativo en la producción (Yami et al., 2000; Ghosh et al., 2007); este efecto se ha atribuido, en parte, a la capacidad de ciertas bacterias del rumen de degradar mimosina y sus metabolitos (Klieve et al., 2002).

No se presentaron diferencias significativas ( $\mathrm{p}>0,05)$ en la producción de metano entre tratamientos (Cuadro 5). En los últimos años, a la utilización como alimento para rumiantes de algunas leguminosas como la leucaena, se le atribuye un efecto en la reducción de las emisiones de gases de efecto invernadero, esto debido a su contenido de compuestos secundarios como los taninos (Jayanegara et al., 2011). En general, se acepta que los taninos pueden afectar la metanogénesis debido a un efecto directo sobre las bacterias metanogénicas ruminales y arqueas, y a un efecto indirecto, sobre la digestión de la fibra para disminuir la producción de hidrógeno, que es un sustrato para estos microorganismos (Tavendale et al., 2005). Además, se ha sugerido que un efecto inhibidor de los taninos en la metanogénesis del rumen, se debe a protozoos asociados a la producción de metano (Hess et al., 2003). Sin embargo, Tiemann et al. (2008) no encontraron cambios en el patrón de fermentación o el número de protozoos cuando el metano se redujo en animales alimentados con leguminosas ricas en taninos condensados. El efecto de los taninos sobre los protozoos, bacterias, hongos y metanógenos del rumen, es variable y en su mayoría dependen del tipo de taninos, su origen y los niveles de suplementación (Patra y Saxena, 2011). Tan et al. (2011) mostraron una reducción en la producción de metano por inclusión de $10 \mathrm{mg}$ de TC/500 mg de MS. Sin embargo, la producción de metano no disminuyó cuando se incorporaron $0,2 \%$ y $1,8 \%$ de taninos condensados en la dieta (Sliwinski et al., 2002; Beauchemin et al., 2007). En el presente estudio la inclusión de 14\% de leucaena en la dieta, representó 1,96 mg de TC/500 mg de MS, correspondiente a 0,39\% de TC de la MS de la dieta. Es posible que el bajo nivel de taninos empleado en las dietas en evaluación (ELC, GLC, EGLC), no haya afectado protozoos, bacterias, hongos y metanógenos del rumen, así como tampoco se vio afectada la degradación de la MS. Makkar (2003) informó que un nivel de taninos entre 2 y $4 \%$ de la MS (límite establecido en rumiantes), no afectó el buen funcionamiento ruminal.

El efecto de los taninos en la reducción de gases de efecto invernadero, se atribuye principalmente a una reducción en la digestión de los alimentos (efecto indirecto) (Barros-Rodríguez et al., 2014); reducción que no se presentó con niveles de inclusión de $14 \%$ de leucaena utilizados en este estudio. Resultados similares fueron reportados por Molina et al. (2013), evaluando in vitro forraje de Guinea y leucaena, solos y sus mezclas $(90: 10,80: 20$ y 70:30, teniendo mayor participación las gramíneas), mediante la técnica de producción de gas, donde la degradación de la materia seca y la producción de metano $\mathrm{g} / \mathrm{kg}$ de MS incubada o $\mathrm{g} / \mathrm{kg}$ de MS degradada a las 48 h de incubación, no fueron disminuidas por el tratamiento.

No se observaron diferencias significativas $(p>0,05)$ para $\mathrm{pH}$, ni para el total de $\mathrm{AGV}$, y aunque el tratamiento LC presentó una mayor proporción de acético y mayor relación acético:propiónico con respecto a todos los tratamientos, los tratamientos que incluían leucaena en la mezcla (ELC, GLC, EGLC), presentaron un comportamiento similar con respecto a los que no la incluían (EC, GC y EGC). Por lo tanto, la inclusión de leucaena en la mezcla no afectó la proporción de AGV.

La presencia de compuestos secundarios en la leucaena, tales como taninos condensados, forman un complejo proteína-tanino que inhibe la actividad de los microorganismos del rumen y resulta en cambios en la ecología del rumen, estos efectos limitan la degradación de los nutrientes y pueden causar una reducción en la producción de ácidos grasos volátiles (AGV) (Ramana et al., 2000; Salem et al., 2006; Galindo et al., 2009). Sin embargo, en el presente estudio un nivel de inclusión de $14 \%$ de leucaena en la dieta, no afectó el pH, ni el total de AGV, debido posiblemente, al bajo nivel de taninos.

El tratamiento que incluía solo leucaena como forraje presentó la mayor proporción significativa de acético y mayor relación acético:propiónico. Cuando se evaluó un sistema silvopastoril intensivo con leucaena, también encontraron un patrón de fermentación ruminal acético (72,17\% molar) (Galindo et al., 2009). 
La proporción molar de isobutírico fue menor para el tratamiento LC vs EGC y GC, debido posiblemente a una menor degradación de la proteína, con respecto a estas gramíneas. La utilización de fuentes proteicas propician mayor disponibilidad de compuestos como amoniaco, aminoácidos y péptidos, así como ácidos grasos de cadena corta ramificados, los cuales se producen como resultado de la degradación de las proteínas (Bach et al., 2005). Por lo tanto, al presentarse menor degradación de la proteína (complejo tanino-proteína), se disminuyó la proporción de ácido isobutírico en el tratamiento LC. Sin embargo, este efecto no se presentó en los tratamientos que incluían $14 \%$ de leucaena en la mezcla.

Al comparar el comportamiento de las gramíneas EC contra GC, no se presentaron diferencias significativas $(p>0,05)$ en los parámetros de fermentación y producción de metano, cuando se encontraban solas o en mezcla con leucaena.

La mezcla de leucaena en un $14 \%$ con gramínea y concentrado, tiene un gran potencial en la ganadería, porque no tiene efectos negativos sobre la fermentación ruminal; por el contrario, aumentaron a los ácidos grasos reportados como benéficos para la salud humana tales como ATV, linoleico y linolénico, de suma importancia, dado que el aumento de estos ácidos grasos a nivel ruminal se relaciona con el aumento de ALC c9t11 y de ácidos grasos insaturados, que podría ocurrir en la leche.

Es de esperar que dentro del desarrollo de estrategias que permitan aumentar los ácidos grasos benéficos en la leche de ganaderías colombianas, los sistemas silvopastoriles de leucaena con Estrella y/o Guinea, ofrezcan una ventaja comparativa en la producción de leche con alto contenido de ácido linoleico conjugado c9t11 y mayor proporción de ácidos grasos insaturados.

\section{AGRADECIMIENTOS}

Los autores de este trabajo agradecen la financiación de Colciencias (Proyecto Colciencias No. PRE00503029606), Universidad de Caldas, Universidad de Antioquia (UdeA) y la Universidad de Sucre. Asimismo, resaltan y agradecen el apoyo logístico y técnico del profesor Ricardo Rosero y la colaboración y el acompañamiento de la Fundación CIPAV en el desarrollo del proyecto.

\section{LITERATURA CITADA}

Addis, M., A. Cabiddu, G. Pinna, M. Decandia, G. Piredda, A. Pirisi, and G. Molle. 2005. Milk and cheese fatty acid composition of sheep fed different mediterranean forages with particular reference to CLA cis-9, trans-11. J. Dairy Sci. 88:3443-3454.

Amaro, P., M.R.G. Maia, R.J. Dewhurst, A.J.M. Fonseca, and A.R.J. Cabrita. 2012. Effects of increasing levels of stearidonic acid on methane production in a rumen in vitro system. Anim. Feed Sci. Technol. 173:252- 260.

AOAC (Association of Official Analytical Chemist). 1999. Official Methods of Analysis. 16 ${ }^{\text {th }}$ ed. AOAC International, Gaithersburg, MD, USA.

Bach, A., S. Calsamiglia, and D. Stern. 2005. Nitrogen Metabolism in the rumen. J. Dairy Sci. 88:(E. Suppl.): E9-E21. doi:10.3168/jds.S0022-0302(05)73133-7

Barros-Rodríguez, M., J. Solorio-Sánchez, J.C. Ku-Vera, A. Ayala-Burgos, C. Sandoval-Castro, and G. SolísPérez. 2012. Productive performance and urinary excretion of mimosine metabolites by hairs heep grazing in a silvopastoral system with high densities of Leucaena leucocephala. Trop. Anim. Health Prod. 44:1873-1878.

Barros-Rodríguez, M., C. Sandoval-Castro, J. SolorioSánchez, L. Sarmiento-Franco, R. Rojas-Herrera, and A. Klieve. 2014. Review Leucaena leucocephala in ruminant nutrition. Trop. Subtrop. Agroecosyst. 17: 173-183.

Beauchemin, K.A., S.M. McGinn, T.F. Martinez, and T.A. McAllister. 2007. Use of condensed tannin extract from quebracho trees to reduce methane emissions from cattle. J. Anim. Sci. 85:1990-1996.

Bichi, E., P.G. Toral, G. Hervas, P. Frutos, P. Gomez-Cortes, M. Juarez, and M.A. de la Fuente. 2012. Inhibition of $\Delta 9$-desaturase activity with sterculicacid: effect on the endogenous synthesis of cis-9 18:1 and cis-9, trans-11 18:2 in dairy sheep. J. Dairy Sci. 95:5242-5252.

Cabiddu, A., M. Decandia, L. Salis, G. Scanu, M. Fiori, M. Addis, M. Sitzia, and G. Molle. 2009. Effect of species, cultivar and phonological stage of different forage legumes on herbage fatty acid composition. Ital. J. Anim. Sci. 8:277-279. 
Cabiddu, A., L. Salis, J.K.S. Tweed, G. Molle, M. Decandia, and M.R.F. Lee. 2010. The influence of plant polyphenols on lipolysis and biohydrogenation in dried forages at different phenological stages: in vitro study. J. Sci. Food Agric. 90:829-835.

Carreño, D., G. Hervás, A. Belenguer, P.G. Toral, and P. Frutos. 2014. Ability of different types and doses of tannins to modulate in vitro ruminal biohydrogenation in sheep. In: Proc. Aust. Soc. Anim. Prod., editor, 30th Biennial Conference of Australian Society of Animal Production: First Joint International Symposium on the Nutrition of Herbivores/International Symposium on Ruminant Physiology (ISNH/ISRP). Canbeira, AUS. p. 157.

Chilliard, Y., F. Glasser, A. Ferlay, L. Bernard, J. Rouel, and M. Doreau. 2007. Diet, rumen biohydrogenation and nutritional quality of cow and goat milk fat. Eur. J. Lipid Sci.Technol. 109:828-855.

CONPES (Consejo Nacional de Política Económica y Social). 2010. Política nacional para mejorar la competitividad del sector lácteo colombiano, Documento CONPES 3675, Bogotá D.C., COL.

Duque M., R. Noguera, y L.F. Restrepo. 2009. Efecto de la adición de urea protegida y sin protección sobre la cinética de degradación in vitro del pasto estrella (Cynodon nlemfluensis) y caña de azúcar (Saccharum officinarum). Livest. Res. Rural Develop. 21(4). http:// www.lrrd.org/lrrd21/4/duqu21058.htm (consultado 20 nov. 2014).

France, J., J. Dijkstra, M.S. Dhanoa, S. Lopez, and A. Bannink. 2000. Estimating the extent of degradation of ruminant feeds from a description of their gas production profiles observed in vitro: derivation of models and other mathematical considerations. Br. J. Nutr. 83:143-150.

Galindo, J., Y. Marrero, T. Ruiz, N. González, A. Díaz, A. Aldama, O. Moreira, J. Hernández, V. Torres, y L. Sarduy. 2009. Efecto de una mezcla múltiple de leguminosas herbáceas y Leucaena leucocephala en la población microbiana y productos fermentativos del rumen de añojos mestizos de Cebú. Rev. Cubana Cienc. Agric. 43:256-264.

García, M.D., G.H. Wencomo, C.M. Gonzáles, R.M. Medina, y O.L. Cova. 2008. Caracterización de diez cultivares forrajeros de Leucaena leucocephala basada en la composición química y la degradabilidad ruminal. Rev. MVZ Córdoba 13:1294-1303.

García-González, R., S. López, M. Fernández, and J.S. González. 2008. Dose-response effects of Rheumofficinale root and Frangula alnusbark on ruminal methane production in vitro. Anim. Feed Sci. Technol. 145:319-334.

Ghosh, M.K., P.P. Atreja, R. Buragohain, and S. Bandyopadhyay. 2007. Influence of short-term Leucaena leucocephala feeding on milk yield and its composition, thyroid hormones, enzyme activity, and secretion of cattle. J. Agric. Sci. 145:407-414.

Griinari, M.K., and D.E. Bauman. 1999. Biosynthesis of conjugated linoleic acid and its incorporation into meat and milk in ruminants. In: M.P. Yurawecz et al., editors, Advances in CLA Research, vol.1, AOCS Press, Champaign, IL, USA. p. 180-200.

Harris, W.S. 2008. Linoleic acid and coronary heart disease. PLEFA 79:169-171.

Hess, H.D., M. Kreuzer, T.E. Díaz, C.E. Lascano, J.E. Carulla, C.R. Soliva, and A. Machmüller. 2003. Saponin rich tropical fruits affect fermentation and methanogenesis in faunated and defaunated rumen fluid. Anim. Feed Sci. Technol. 109:79-94.

IPCC (Intergovernmental Panel on Climate Change). 2007. Climate change 2007: The physical science basis, contribution of working group I to the fourth assessment report of the intergovernmental panel on climate change. http://www.ipcc.ch/publications_ and_data/publications_ipcc_fourth_assessment_ report_wg1_report_the_physical_science_basis.htm (accessed sept. 30 2009).

Jayanegara, A., E. Wina, C.R. Soliva, S. Marquardt, M. Kreuzer, and F. Leiber. 2011. Dependence of forage quality and methanogenic potential of tropical plants on their phenolic fractions as determined by principal component analysis. Anim. Feed Sci. Technol. 163: 231-243.

Johnson, K.A., and D.E. Johnson. 1995. Methane emissions from cattle. J. Anim. Sci. 73:2483-2492.

Khiaosa-Ard, R., S.F. Bryner, M.R. Scheeder, H.R. Wettstein, F. Leiber, M. Kreuzer, and C.R. Soliva. 2009. Evidence for the inhibition of the terminal step of ruminal alpha-linolenic acid biohydrogenation by condensed tannins. J. Dairy Sci. 92:177-88.

Klieve, A.V., D. Ouwerkerk, A. Turner, and R. Roberton. 2002. The production and storage of a fermentorgrown bacterial culture containing Synergistes jonesii, for protecting cattle against mimosine and 3-hydroxy-4 (1H)-pyridone toxicity from feeding on Leucaena leucocephala. Aust. J. Agric. Res. 53:1-5.

Krebsky, E.O., J.M.C. Geuns, and M. De Proft. 1996. Fatty acids in polar lipids from etiolated Cichorium intybus. Phytochemistry 43:747-751. 
Lassey, K.R., M.J. Ulyatt, R.J Martin, C.F. Walker, and I.D. Shelton. 1997. Methane emissions measured directly from grazing livestock in New Zealand. Atmosph. Environ. 31:2905-2914.

Lee, M.R.F., S.A. Huws, N.D. Scollan, and R.J. Dewhurst. 2007. Effects of fatty acid oxidation products (green odor) on rumen bacterial populations and lipid metabolism in vitro. J. Dairy Sci. 90:3874-3882.

López, S., and C.J. Newbold. 2007. Analysis of methane. In: P.S. Harinder et al., editors, Measuring methane production from ruminants. Makkar, Springer, NY, USA. p. 7-10.

Mahecha L., C.V. Durán, M. Rosales, C.H. Molina, y E. Molina. 2000. Consumo de pasto estrella Africana (Cynodon plectostachyus) y leucaena (Leucaena leucocephala) en un sistema silvopastoril. Pasturas Trop. 22 (1):26-30.

Mahecha, L., J. Angulo, B. Salazar, M. Cerón, J. Gallo, C.H. Molina, J.E. Molina, J.F. Suárez, J.J. Lopera, and M. Olivera. 2008. Supplementation with bypass fat in silvopastoral systems diminishes the ratio of milk saturated/unsaturated fatty acids. Trop. Anim. Health Prod. 40:209-216.

Makkar, H.P.S. 2003. Quantification of tannins in tree and shrub foliage. A laboratory manual. Kluwer Academic Publishers, HOL.

McDougall, E.I. 1948. Studies on ruminant saliva. 1. The composition and output of sheep's saliva. Biochem. J. 43(1):99.

Mele, M., M. del Viva, A. Serra, G. Conte, and P. Secchiari. 2006. Effect of forage/concentrate ratio and soybean oil supplementation on C18:1 and CLA isomers in milk fat from Saanen goats. In: Proceedings of the 4th Euro Fed Lipid Congress, 1-4 oct. 2006, University of Madrid (UCM), ESP.

Menke, K.H., and H. Steingass. 1988. Estimation of the energetic feed value obtained from chemical analysis and in vitro gas production using rumen fluid. Anim. Res. Dev. 28:7-55.

Minieri S., A. Buccioni, S. Rapaccini, A. Pezzati, D. Benvenuti, A. Serra, and M. Mele. 2014. Effect of quebracho tannin extract on soybean and linseed oil biohydrogenation by solid associated bacteria: an in vitro study. Ital. J. Anim. Sci. 13:604-608.

Mohammed, R., M. O’Donovan, C.S. Stanton, J.F. Mee, J.J. Murphy, D. Glimm, and J.J. Kennelly. 2006. Effect of grazed grass, zero-grazed grass and conserved grass on transvaccenic acid and cis- 9 , trans-11 conjugated linoleic acid concentrations in rumen, plasma and milk of dairy cows. In: Proceedings of the 4th Euro Fed Lipid Congress, 1-4 oct. 2006, University of Madrid (UCM), ESP.

Molina, I.C., J.M. Cantet, S. Montoya, G.A. Correa, y R. Barahona. 2013. Producción de metano in vitro de dos gramíneas tropicales solas y mezcladas con Leucaena leucocephala o Gliricidia sepium. Rev. CES Med. Zootec. 8(2):15-31.

Monforte-Briceño,G.,C.Sandoval-Castro,L.Ramírez-Avilíes, and M. Capetillo-Leal. 2005. Defaunating capacity of tropical fodder trees: effects of polyethyleneglycol and its relationship to in vitro gas production. Anim. Feed Sci. Technol. 123/124: 313-327.

Mosley, E.E., M.K. McGuire, J.E. Williams, and M.A. McGuire. 2006. Cis-9, trans-11 conjugated linoleic acid is synthesized from vaccenic acid in lactating women. J. Nutr. 136:2297-2301.

Moss, A.R., J.P. Jouany, and J. Newbold. 2000. Methane production by ruminants: Its contribution to global warming. Ann. Zootech. 49:231-253.

Murgueitio, E. 1999. Environmental and social adjustment of the cattle farming sector in Colombia. World Anim. Rev. 93:2-15.

Pagiola, S., P. Agostini, J. Gobbi, C. de Haan, M. Ibrahim, E. Murgueitio, E. Ramirez, M. Rosales, and J.P. Ruiz. 2005. Paying for biodiversity conservation services Experience in Colombia, Costa Rica, and Nicaragua. Mountain Res. Dev. 25:206-211.

Pagiola, S., E. Ramirez, J. Gobbi, C. De Haan, M. Ibrahim, E. Murgueitio, and J.P. Ruiz. 2007. Paying for the environmental services of silvopastoral practices in Nicaragua. Ecol. Econ. 64:374-385.

Palmquist, D.L. 2007. Biohydrogenation then and now. Eur. J. Lipid Sci. Technol. 109:737-739.

Patra, A.K., and J. Saxena. 2011. Exploitation of dietary tannins to improve rumen metabolism and ruminant nutrition. J. Sci. Food Agric. 91:24-37.

Posada, S.L., R. Noguera, y D. Bolívar. 2006. Relación entre presión y volumen para la implementación de la técnica in vitro de producción de gases. Rev. Col. Cienc. Pec. 19:407-414.

Ramana, D.B.V., S. Sultan, K.R. Solanki, and A.S. Negi. 2000. Nutritive evaluation of some nitrogen and nonnitrogen fixing multipurpose tree species. Anim. Feed Sci. Tecnol. 88:103-111.

Rodríguez-Echevarría, M.E., G. Corral-Flores, B. SolorioSánchez, A.D. Alarcón-Rojo, J.A. Grado-Ahuir, C. Rodríguez-Muela, L. Cortés-Palacios, V.E. SegoviaBeltrán, y F.J. Solorio-Sánchez. 2013. Calidad de la carne de bovinos engordados en un sistema 
silvopastoril intensivo en dos épocas del año. Trop. Subtrop. Agroecosyst. 16:235-241.

Ryhänen, E., K. Tallavaara, J. Griinari, S. Jaakkola, S. Mantere-Alhonen, and K. Shingfield. 2005. Production of conjugated linoleic acid enriched milk and dairy products from cows receiving grass silage supplemented with a cereal-based concentrate containing rapeseed oil. Int. Dairy J. 15:207-217.

Salem, A.Z.M., M.Z.M. Salem, M.M. El-Adawy, and P.H. Robinson. 2006. Nutritive evaluations of some browse tree foliages during the dry season: secondary compounds, feed intake and in vivo digestibility in sheep and goats. Anim. Feed Sci. Technol. 127:251-267.

Sallam, S.M.A., I.C. da Silva Bueno, P.B. de Godoy, E.F. Nozella, D.M.S.S. Vitti, and A.L. Abdalla. 2010. Ruminal fermentation and tannins bioactivity of some browses using a semi-automated gas production technique. Trop. Subtrop. Agroecosyst. 12:1-10.

SAS. 2004.Version 9.1.3. SAS Institute Inc., Cary, NC, USA.

Sheehle, E.A., and D. Kruger. 2006. Global anthropogenic methane and nitrous oxide emissions. Energy J. 27(special issue 3):33-44.

Sliwinski, B.J., M. Kreuzer, H.R. Wettstein, and A. Machmüller. 2002. Rumen fermentation and nitrogen balance of lambs fed diets containing plant extracts rich in tannins and saponins, and associated emissions of nitrogen and methane. Arch. Anim. Nutr. 56:379-392.

Soltan, Y.A., A.S. Morsy, S.M.A. Sallam, R.C. Lucas, H. Louvandini, M. Kreuzer, and A.L. Abdalla. 2013. Contribution of condensed tannins and mimosine to the methane mitigation caused by feeding Leucaena leucocephala. Arch. Anim. Nutr. 67:169-184.

Tan, H.Y., C.C. Sieo, N. Abdullah, J.B. Liang, and X.D. Huang. 2011. Effects of condensed tannins from Leucaena on methane production, rumen fermentation and populations of methanogens and protozoa in vitro. Anim. Feed Sci. Technol. 169:185-193.

Tavendale, M.H., L.P. Meagher, D. Pacheco, N. Walker, G.T. Attwood, and S. Sivakumaran. 2005. Methane production from in vitro rumen incubations with Lotus pedunculatus and Medicago sativa, and effects of extractable condensed tannin fractions on methanogenesis. Anim. Feed Sci. Technol. 123/124: 403-419.

Tequin-Ocampo, E.B. 2014. Estudio de la influencia de la suplementación lipídica en la dieta de bovinos sobre los ácidos grasos funcionales de la leche y la producción de metano y ácidos grasos volátiles del fluido ruminal por cromatografía de gases. Tesis MSc. Universidad de Caldas, Manizales, COL.

Theodorou, M.K., B.A. Williams, M.S. Dhanoa, A.B. McAllan, and J. France. 1994. A simple gas production method using a pressure transducer to determine the fermentation kinetics of ruminant feeds. Anim. Feed Sci. Technol. 48:185-197.

Tiemann, T.T., C.E. Lascano, H.R. Wettstein, A.C. Mayer, M. Kreuzer, and H.D. Hess. 2008. Effect of the tropical tannin-rich shrub legumes Calliandra calothyrsus and Flemingia macrophylla on methane emission and nitrogen and energy balance in growing lambs. Anim. 2:790-799.

Vasta, V., H.P.S. Makkar, M. Mele, and A. Priolo. 2009. Ruminal biohydrogenation as affected by tannins in vitro. Brit. J. Nutr. 102:82-92.

Van Soest, P.J., J.B. Robertson, and B.A. Lewis. 1991. Methods for dietary fiber, neutral detergent fiber and non starch polysaccharides in relation to animal nutrition. J. Dairy Sci. 74:3583-3597.

Yami, A., A.J. Litherland, J.J. David, T. Sahlu, R. Puchala, and A.L. Goetsch. 2000. Effect of dietary level of Leucaena leucocephala on performance of Angora and Spanish doelings. Small Ruminant Res. 38:17-27.

Weiss, M.F., F.A. Martz, and C.L. Lorenzen. 2004a. Conjugated linoleic acid: Historical context and implications. Prof. Anim. Sci. 20:118-126.

Weiss, M.F., F.A. Martz, and C.L. Lorenzen. 2004b. Conjugated linoleic acid: Implicated mechanisms related to cancer, atherosclerosis and obesity. Prof. Anim. Sci. 20:127-135. 